\title{
Research on the Financing Dilemma of Chinese Private Enterprises
}

\author{
Jin Yaqi ${ }^{1, a}$ Du Yulan ${ }^{2 *}$ \\ ${ }^{1}$ School of Economics and Management,Nanjing University of Science and Technology, NanJing,JiangSu,China \\ 2School of Economics and Management,Nanjing University of Science and Technology, NanJing,JiangSu,China \\ a1026851021@qq.com
}

\begin{abstract}
In recent years, China's economic development momentum has been relatively rapid. Under this situation, private enterprises have also grown up and have become an essential factor in China's economic development. On the one hand, it provides a lot of employment opportunities for the residents of our country, which is conducive to enhancing people's income level and improving people's quality of life. On the other hand, it also contributes to the stability and harmony of the society. However, at the present stage, our private enterprises also encountered some difficulties in the development process, such as difficulties in financing. The difficulties encountered by private enterprises have hindered their further development, and also made them less resistant to market risks. Based on the market environment of private enterprises, this paper focuses on the existing financing difficulties of private enterprises, explores the financing channels of our private enterprises, and explores specific measures for our private enterprises to cope with the financing dilemma based on relevant domestic and foreign theories. This article elaborates on the definition of private enterprises and introduces different financing methods in detail. This article also studies foreign financing measures, and tries to find a financing method suitable for our private enterprises. At the end of the article, some specific suggestions are made for improving the financing status of private enterprises.
\end{abstract}

Keywords: private enterprise, financing status, financing dilemma, financing countermeasure

\section{INTRODUCTION}

\subsection{Background and significance of topic selection}

In today's society, while China's economy is developing at a high speed, people's consumption concepts are constantly changing, and people's demand for various products is constantly increasing. As the business model of a private enterprise is not restricted to traditional business methods and its market adaptability is strong, its position in meeting social needs has become increasingly important. According to reports, by the end of 2011, the share of China's private enterprises in China's existing enterprises was close to $90 \%$, the number of registered enterprises reached more than 9 million, and the number of self-employed enterprises had reached more than 40 million [3]. The tax revenue from private enterprises is close to $50 \%$ of the total tax revenue. The importance of private enterprises in China's non-public ownership enterprises has been increasing. Private enterprises have made outstanding contributions in the process of China's GDP growth, solving employment problems, and increasing fiscal revenue. The development prospects of private enterprises have shown a bright future. But even so, even the best things face certain problems, and the most prominent problem in the development of our private enterprises is the financing problem. In the process of expanding our own scale, the private funds of private enterprises are not enough to support the expansion of the enterprise. However, it is not easy for private enterprises to pool funds through traditional models. A large part of this cause is directly related to China's existing banking system, because China's existing banking system is more favored by large and medium-sized state-owned enterprises, and the development of financing intermediaries is weak, and its own mechanism is not perfect. This makes it difficult to raise funds for the development of private enterprises.

\subsection{Literature review}

\subsubsection{Domestic literature review}

$\mathrm{Wu}$ Jianxiong [9] analyzed the specific problems encountered by private enterprises in financing, such as low corporate credibility, imperfect self-management mechanisms, and proposed corresponding solutions to different subjects. Xiao Jianhua [10] and Wang Qi [10] discussed that China's financing system for private enterprises is not yet perfect, and it is necessary to further establish corresponding laws and regulations for the development of private enterprises to improve the conditions for financing private enterprises. $\mathrm{Hu}$ 
Yuancheng [3] explored the different characteristics of private enterprise financing from the private enterprise itself. For example, private enterprise financing can start from two aspects: direct financing and indirect financing. Bian Weiqiang [11] proposed that financing has not entered the normal channels, and credit guarantees have not yet formed. He analyzed the factors affecting financing from three aspects: financial institutions, enterprises, and national policies. The countermeasures are conducive to improving the overall quality and strength of private enterprises and standardizing their financial systems. Liu Qianwei[12] and Yang Weishu[12] believe that the financing channels of private enterprises in China mainly include internal financing and external financing, and internal financing is the main channel of funding for private enterprises. They thought that only by actively promoting the innovation of the operating services and institutional mechanisms of private enterprises, and the government's support in policy, could it effectively solve the problem of financing difficulties for private enterprises and contribute to the development of China's national economy.

\subsubsection{Review of Foreign Literature}

Wiilialn [7] and Bradford [7] demonstrated that the government is very helpful to the issue of credit guarantees for private enterprises. It can help to ease the financing pressure of private enterprises and obtain loans from financial intermediaries by formulating relevant policies. The government can divide the departments that focus on helping private enterprises to finance, to specifically help private enterprises solve the problem of financing difficulties. Stiglitz [6] and Weiss [6] demonstrated that the large scale of the company's capital requirements is a common phenomenon in today's society, but due to the lack of mutual understanding between the two parties and the existence of certain risks, it is difficult for banks to make accurate judgments on the specific situation of private enterprises. This makes it difficult for private enterprises to obtain loans. In the general social environment, professional credit rating agencies can be established to classify the credit ratings of private enterprises so that financial institutions such as banks can grant loans based on the credit ratings of private enterprises. Yan Shen [8] pointed out that a better bank-enterprise relationship is conducive to the smooth financing of private enterprises. Enterprises should maintain a good relationship with the bank and actively provide their own details to the bank, which is conducive to enhancing the bank's understanding of itself. In order to facilitate their smooth financing.

\subsection{The main structure and research method of the paper}

\subsubsection{Research method}

While the research in this paper combines theory with practice, it also adopts many methods to conduct structural analysis and research on the subject of this paper. This article uses different research methods to discuss the subject, the purpose of which is to systematically elaborate on the problems generated by private enterprises and the countermeasures of each subject, in order to make this research closer to actual life and make it more It has realistic meaning.

(1) Literature research method. What it is talking about is a more commonly used method based on the arguments that the author wants to research, and then collecting information so that the problem to be researched can be discussed more accurately.

(2) Information research method. It refers to a method of researching the argument using the collection of relevant information. Today's society is an era of "informatization." A large number of information resources circulate in our environment, and these resources can be developed for our own use. This is a novel research method that can reveal the more essential development law of things and help people to research and explore problems.

(3) Descriptive research method. Its use is relatively simple. It studies existing phenomena, laws and theories, and then narrates and explains them. Although it also refers to a more general theory, which is also a common usage in writing, the most important thing is that it plays a greater role in the problem to be studied.

\subsubsection{The main structure}

The thesis is divided into six parts. The first part is the background and significance of the research. The second part studies the existing financing channels and financing theories of private enterprises. The third part analyzes the existing financing dilemmas of private enterprises and analyzes Its causes; the fourth part proposes relevant solutions to the problems they face; the fifth part explains the deficiencies of this article; the sixth part is the thanks of this article.

\section{BRIEF INTRODUCTION OF FINANCING CHANNELS AND FINANCING THEORY}

\subsection{Basic concepts of financing}

Financing means that in order to expand its production scale and promote its own development, the company raises funds from the public or certain financial institutions 
to ensure long-term development. Generally speaking, the purpose of corporate financing is threefold: corporate financing to expand production scale, corporate financing to repay previously owed loans, and both. In a broad sense, financing is also called finance, which refers to the borrowing and lending of funds, the behavior of shortfalls to pool funds through the capital market, and the behavior of rich people to release funds.

\subsection{Financing channels}

The rapid development of China's economy has led to the rapid development of financial markets, which has opened up the way for financing of private enterprises in China. However, the main financing channels are divided into two parts, one is internal financing and the other is external financing.

\subsection{1 .Financing channels}

The rapid development of China's economy has led to the rapid development of financial markets, which has opened up the way for financing of private enterprises in China. However, the main financing channels are divided into two parts, one is internal financing and the other is external financing.

\subsubsection{Endogenous financing concept and advantages and disadvantages}

(1) The concept of endogenous financing

The meaning of endogenous financing is classified according to the specific types of different enterprises. What is commonly referred to as endogenous financing refers to the fact that the owner of an enterprise relies on its own funds for financing. It mainly includes retained profits and depreciation. It talks about the process by which companies convert their reserve capital into investment. Endogenous financing has the characteristics of fundamental, independent, low cost and strong resistance to the emergence of corporate funds. In fact, in economically prosperous regions, endogenous financing is the backbone of its financing, and it is the nourishment for the survival and continued development of enterprises.

(2) Advantages and disadvantages of endogenous financing Advantages: First, autonomy. The main source of endogenous financing is the investor's own funds. Enterprises can use it freely without being subject to many restrictions. Second, low financing costs. Because the company uses its own funds, it does not need to pay interest, pay intermediary agency fees, etc. like external funds, so the company has a high undistributed profit and provides sufficient financial support for the development of the company. Third, the original shareholders' equity and actual control rights remain unchanged. Because the increase in undistributed profits does not reduce shareholders' equity, it can also help companies develop. Fourth, reduce the tax paid by shareholders. For example, if a company distributes undivided profits to shareholders, it is required to pay taxes in accordance with China's existing tax system. However, if the company does not distribute dividends, it may raise the company's stock price, and shareholders can sell their stocks to increase their own profits and reduce the actual taxes paid by shareholders. Disadvantages: First, endogenous financing is greatly influenced by the company itself. For example, a company's managers have lower management capabilities, which can result in less corporate profits, or less profits from the enterprise, and less capital the company can raise. Second, the proportion of distributed dividends is important to consider the wishes of different shareholders. Because they may guarantee their own interests to the greatest extent, they are required to keep the proportion of dividends distributed by companies within a certain range, that is, the proportion of undistributed profits cannot be too large. This may cause the financing of the enterprise to be restricted, thereby restricting the development of the enterprise. Third, the chain reaction brought by the small distribution of dividends. If the distribution of dividends is small, it may be insufficiently attractive for external financing. Because paying less dividends may indicate that the company's operating efficiency is poor, and the actual controller of the company has poor planning ability for the company's development, so that people can't see the hope of the company's development, which affects external financing.

\subsubsection{The concept and advantages and disadvantages of external financing}

(1) The concept of external financing

External financing refers to the process in which an enterprise raises funds from the public. When the company's own funds cannot meet its production needs, the company will consider raising funds from the public.

(2) Advantages and disadvantages of external financing

The advantage of external financing is that enterprises can raise funds from more ways, and the financing methods are various, and the application is more flexible, which can meet the specific financing needs of different demanders, so that the funds can be used more fully. The most important thing is that it is also a bridge connecting the supply and demand of funds in the market. Without it, the financial industry in the modern sense would cease to exist.

The disadvantage of external financing is that it has high standards, needs to pay intermediary fees, and there are some unpredictable dangers in the specific implementation process. It has high requirements for the demanders of funds, especially for public financing. For example, if it raises funds from the public, it must meet the specific provisions formulated by the relevant departments. Otherwise, it will be difficult to obtain loans and the financing costs paid are many. It will increase the extra 
burden of the enterprise and increase the extra costs of the enterprise, which will also have a large adverse impact on the long-term survival of the enterprise.

At present, China is still a developing country in the initial stage of market-oriented reforms. It is in the initial stage of socialist development. China 's GDP is lower than the world 's average standard, and the history of China 's stock exchange market is relatively short. The development of this mechanism is also imperfect. For this reason, the financing of our country's enterprises follows a progressive approach. Drawing on common practices in foreign countries and combining the current situation in China, indirect financing can be used as the backbone, and direct financing can be used as the financing arrangement for branches. But the most important thing is to refer to your own actual situation and carry out institutional innovation to establish a market economy microeconomic subject.

\section{3 .Brief Introduction to Major Financing Theories at Home and Abroad}

The most important thing for an enterprise to achieve sustainable development is whether it can stabilize the supply of funds. The following conclusions summarize and review the research methods and research results of the financing theory of private enterprises, explore the building blocks of related theoretical buildings of private enterprises, and explore future research directions that have greater value and significance in the financing of private enterprises.

\subsubsection{Myers \& Majuf1984 sequential financing theory model}

Myers \& Majuf's[13] discussion on corporate financing shows that, because the information about the supply and demand of funds cannot fully understand each other, there is a problem of adverse selection. An enterprise needs a large amount of funds for the expansion of its own scale or the implementation of a new development plan to conduct stock financing. However, due to the problem of adverse selection, the actual value of the stock will be underestimated, which will cause the stock price to fall and the value of the enterprise. Reduced content. When the price of the stock drops to such an extent that the investor's future expected return is lower than the funds invested, the investor will withdraw the funds and no longer invest.

\subsubsection{Grossman and Hart's debt guarantee theory}

Based on the agency cost model[14], a more in-depth study of how financing with bonds can alleviate the contradiction between corporate decision makers and corporate shareholders. They believe that in the period when the proportion of corporate debt financing is rising, corporate decision makers may increase the risk of corporate closure due to various reasons. If the company goes bankrupt, the decision makers may bear a series of chain consequences, such as They say that their own funds have decreased, the company's actual operation rights have been transferred, and personal reputation has fallen.

\section{CURRENT SITUATION AND PROBLEMS OF FINANCING OF PRIVATE ENTERPRISES IN CHINA}

\section{1 . Status of Financing of Private Enterprises in China}

The difficulty of financing encountered by private enterprises also generally appears in the world's financial markets, especially those small-scale and short-lived private enterprises, in addition to the use of endogenous financing, it is particularly difficult to obtain external funding support, Raising funds is particularly difficult. Since the reform and opening up for many years, our government has been working hard to solve the problem of capital growth and development of private enterprises, and to solve the bottlenecks of private enterprise development from both direct and indirect financing. The financing conditions of enterprises have been greatly improved. But up to now, the primary source of funds for companies is mainly banks. But so many years of experience in capital circulation show that financial institutions with large amounts of funds are more inclined to give loans to companies with higher credit and larger development scales. The existing development of private enterprises is not enough to get their favor, so from the first The three parties' financial institutions have raised funds to meet their own operational needs.

\subsection{Existing Problems in the Financing Status of Chinese Private Enterprises}

\subsubsection{Unreasonable financing structure and high cost}

The development of private enterprises is basically based on their own capital accumulation. The proportion of internal financing in capital far exceeds that of external financing. The simple form of financing layout may prevent the long-term development of enterprises. Furthermore, in external financing, private enterprises have only one option for bank loans. At the same time, when the bank lends, all that can be given to enterprises is short-term loans. Private enterprises enjoy relatively few preferential policies when lending, and the procedures are cumbersome, and the guarantees provided by the 
enterprises are also many. All of the above have become a stumbling block for private enterprises to raise funds.

\subsubsection{Reasons for financing difficulties caused by private enterprises themselves}

The products of private enterprises in China have low technological content, small scale, lack of management mechanism, and low R \& D capabilities. Most of them are processing companies, only earning low processing costs, without their own brand effects. Nowadays, as the degree of opening up to the outside world is getting higher and higher, the risks associated with it are also increasing. In order to sell goods between different companies, most of them rely on price wars to sell goods, which also causes resources. The huge waste has left companies without the funds to make their own trademarks and open up their own world. This makes the bank's borrowing risk even higher, and the financing difficulty of private enterprises has risen to another level.

\subsubsection{The institutional innovation of enterprises is not synchronized with market changes}

With the rapid development of the Chinese economy, the development of Chinese private enterprises has entered a period of rapid growth. At present, China's existing private enterprises mainly include three models; the first is the emergence of private enterprises and individual industrial and commercial households in the early stage of reform; the second is a group of enterprises formed by the state-owned enterprise through underwriting and leasing models; the third is the "company Corporations appearing after the law was promulgated. At present, the atmosphere of financing in China's market is very uneven. The most prominent form is the country's growth strategy and changes in market conditions. However, because the system reform of private enterprises cannot keep up with the changes in the external environment of the market, unsuitable situations will occur, and the worst will cause corporate bankruptcy.

\subsection{External environmental problems in the current financing situation of Chinese private enterprises}

\subsubsection{High threshold for banks}

When a state-controlled commercial bank issues a loan, it is more about the size and operating efficiency of the company. The purpose of the loan is not to consider the future income of the project and the business performance of the company, but to focus on the business The nature and scale of private enterprises, even if private enterprises are good at business, the credit is still very difficult to obtain bank loans, private enterprises want to obtain loans is difficult.

\subsection{2 .Mortgage difficulties}

Corporate loans still need to be guaranteed, but there are really few intermediary agencies that can guarantee them. The few guarantee intermediary agencies are also relatively small in scale and cannot have sufficient funds to provide to enterprises. Not only that, most of the intermediary agencies are set up in large-scale cities, there are few in small places, and corporate guarantees are even more difficult. In accordance with their actual interests, in order to ensure the smooth recovery of loans, banks will also choose companies with higher credit and better development prospects. Even if some companies qualify for the loan, the guarantee is not enough to support them. There are also some companies guaranteeing each other, but this kind of guarantee is relatively risky. Assuming that one of them has an irreparable problem, a series of companies may be overwhelmed.

\subsubsection{Obstruction of financing channels}

China's current financing model can be really applied by private enterprises. Bank loans are still the first choice of financing for private enterprises. However, the approval of bank loans is complex, and loans tend to be large and medium-sized enterprises, and there are fewer loans to private enterprises. For this reason, private enterprises should not stick to the existing model and should actively explore new paths.

\subsubsection{The enterprise's credit rating mechanism urgently needs to be established}

The existence of private enterprises in China is relatively short, and the credit level recorded is relatively rare. In addition, the development and operation status of the company, the efficiency of the company's use of funds, and the professional quality of the company's operators are difficult to know as much as the external environment of state-owned enterprises. Therefore, a series of measures that commercial banks usually use for the credit of state-owned enterprises are difficult to use in the investigation of private enterprises[1]. 


\subsection{Actively play the role of government support}

\section{COUNTERMEASURES FOR FINANCING PROBLEMS OF CHINESE PRIVATE ENTERPRISES}

\subsection{China's private enterprises should strengthen their own quality and improve financing capabilities}

\subsubsection{Construction of Private Enterprises' Financing Ability}

In order to alleviate the financing crisis of private enterprises, not only does the state need to establish relevant systems to improve the ability of corporate financing, but the enterprises themselves must also make corresponding changes. Private enterprises should take the initiative to understand the specific knowledge of financing and increase the diversification of financing channels. And we must have a clear grasp of the advantages and characteristics of our own operations. Improve the efficiency of the use of funds and rationally allocate funds to achieve the best use of funds.

\subsubsection{Credit building of private enterprises}

Private enterprises should continue to carry out self-reform and improve their own management systems, which can promote the improvement of corporate operating efficiency and corporate reputation. If an enterprise wants to survive the competition, it must increase its own trust. In this case, when the enterprise raises funds from the outside world, investment talents have higher trust in the enterprise, which enables the enterprise to successfully finance.

\subsubsection{Improve the relationship between businesses and banks}

Banks are now a major provider of corporate funding requirements, so companies should strengthen information sharing with banks, so that banks can clearly understand the company's current situation and future prospects, which can help banks to improve corporate credibility. grasp. If the cooperation between different private enterprises in a small area is closer, the credit of the group can also be used to enhance the development of the enterprise's own credit so that it can play an increased role.

\subsubsection{Improve corresponding laws and regulations and establish a credit rating system}

One of the most important problems that private enterprises face in the current financial market is the asymmetry of information between the two parties. Banks and other financial institutions cannot make accurate assessments of whether the credit of private enterprises is good, and private enterprises cannot provide relatively effective information. Credentials to prove their creditworthiness. To this end, the state should build a bridge of trust between the two sides so that the lenders of funds have a better understanding of private enterprises, which is conducive to the smooth financing of private enterprises [3].

\subsubsection{Increased proportion of policy support funds for private enterprises}

Private enterprises have less investment in infrastructure construction, a single production variety, and inefficient use of funds, which makes them less resistant to the crisis. When the financial crisis comes, private enterprises will suffer large-scale bankruptcy due to insufficient funds. In addition, because private enterprises cannot repay the borrowed funds, illegal private loans are used to repay bank loans, which also increases the risks of private enterprises themselves. To this end, the state can help private enterprises to raise funds from various aspects and reduce the pressure on financing of private enterprises.

\subsubsection{Continuously improve the financial service system}

The state urgently needs to establish an institutional framework suitable for the use of private enterprises, attach importance to the needs of private enterprises, and promote the implementation of relevant policies suitable for financing of private enterprises. The state can also set up some state-controlled banks that specialize in responding to loans from private enterprises. It can also divide the existing policy banks into a department that can help private enterprises to lend to help private enterprises get loans smoothly. 
relevant information of private enterprises is difficult to verify, only a qualitative description was made during the analysis. The empirical analysis of this paper has many shortcomings.

\subsubsection{Establish a credit guarantee system suitable for private enterprises}

Establishing a corresponding credit evaluation system can effectively help the smooth development of private enterprise financing, which can be considered from three places: (1) For companies with relatively little need for money financing, you can use the capital and projects of the enterprise as collateral, and try Gradually forming a relatively complete system for private enterprise loans; (2) In order to further ensure the smooth progress of private enterprise loans, you can experiment with a government, enterprise, and financial institution cooperating with a guarantee institution to establish a guarantee fund to implement the implementation of private enterprise loans Guarantees; (3) There are some loans for private enterprises, which can be tested by multi-family joint guarantees to help enterprises complete financing smoothly [4].

\subsubsection{Actively expand the financing market of private enterprises}

Studies in the more developed regions of the world market economy show that financing on the stock market is an important channel for private enterprises. Now, as the progress of private enterprises has entered a normal track, more and more private enterprises have taken listing as the most important item on the corporate calendar, and it is also the last stage for enterprises to thrive. Private enterprises with high technological content can be allowed to enter the stock market for financing. Among these enterprises, those with promising development prospects can raise funds through listing.

\section{CONCLUSION}

The development of private enterprises is based on a reasonable allocation of capital structure, which provides sufficient impetus for the further development of China's future economy. However, since the end of the last century, private enterprises have faced more and more difficulties. The difficult financing situation of private enterprises hinders the development prospects of the enterprises. If they cannot be solved well, it may cause greater obstacles to the sustainable development of China's economy and society. For this reason, based on China's basic national conditions, proceeding from the actual needs of society, and good at learning from foreign successful experiences, it is of great significance for the development of China's private enterprises to propose specific financing difficulties.In this article, the author analyzes as many specific examples as possible, but since the specific

\section{ACKNOWLEDGMENTS}

Thanks to the relevant reference materials provided by the School of Economics and Management of Nanjing University of Science and Technology, and thanks to Mr. Du Yulan for the valuable amendments to this article. Due to the limited level of this theory, there are unavoidable omissions and shortcomings in the thesis's induction and elaboration of corporate financing dilemmas. Teachers and experts are welcome to correct it.

\section{REFERENCES}

[1] Cui Yan. Literature review of domestic SME financing issues [J]. Knowledge Economy, 2010 (03).

[2] Hu Guoping. Discussion on the Financing Problems and Countermeasures of Private Enterprises [J]. Modern Business Industry. 2010, 22 (21).

[3] Hu Yuancheng. Investigation and Thinking of SME Financing [J]. Management World, 2004 (04).

[4] Li Ying. Discussion on the Financing of Private Enterprises in China [J]. Journal of Sun Yat-sen University, 2006, 26.

[5] Anderson , V. \& Skinner , D.Organizational learning in practice:how do small businesses learn to operate internationally?Human Resource Development International,1999,2 (3) :235-259

[6] Joseph E.Stiglitz and Andrew Weiss.Credit Rationing in Markets with Imperfect Information. The.American Economic Review,1981,71,393-410.

[7] William D.Bradford.Creating Government Financing Programs for Small and Medium Sized Enterprises in China(J1.China and World Economv,2004,3-4.

[8] Yan Shen. Bank Size and Small and Medium Sized Enterprise Lending:Evidence from ChinafJl.World Development,2009,37,50-56.

[9] Wu Jianxiong. An Analysis of the Financing of Private Enterprises [J]. Silk Road. 2011 (2).

[10] Xiao Jianhua, Wang Qi. Letter of Legal System for Financing of Private Enterprises to be Improved [N]. Economic Daily 2001.12.

[11] Bian Weiqiang.Discussion on the Financing of Small and Medium-sized Private Enterprises 
[J] .Research on Financial and Economic Issues, 2014 (05).

[12] Liu Qianwei, Yang Yashu.Analysis of the Causes and Countermeasures of Difficulties in Financing of Chinese Private Enterprises [J] .China Business, 2011 (05).

[13] Myer,S.C.\&Majluf, N.Corporate Financing ang Investment Decisions when Firms have Information That Investors Do Not Have [J].Journal of Financial Economics,1984,(13):187-221.

[14] Grossman S,Hart O D.Corporate financial structure and managerial incentives[M].Chicago.University of Chicago Press, 1982:107-140. 